\title{
Strategy Analysis: Fancy Feet Running Gear
}

\author{
Joy Cooper \\ Texas A\&M University-Texarkana \\ Larry Davis
Texas A\&M University-Texarkana
}

This paper analyzes the target market responses and product offerings of organization strategy decisions of a small specialty retail company. A survey was conducted, and results were analyzed and presented based on the strategies as presented in The Discipline of Market Leaders: Choose Your Customers, Narrow Your Focus, Dominate Your Market (Treacy \& Wiersema, 1995). The paper navigates through the external and internal change process considerations that impact the operation of a specialty retail business within a fluid retail market in a rural geographical environment. The research provided a view of owner, employee, and customer perspectives related to the store. Employees expressed the ability to be creative, conduct research and have a level of autonomy. It also showed that operational excellence is not the highest ranked element and that shoppers are attached to the convenience of local shopping. The store appeared to recognize emerging needs of the target market and assess customer response to the organization's strategic decisions.

Keywords: strategy, coaching, target market, SWAT Analysis, Values Model Analysis

\section{INTRODUCTION}

This paper is an account of a family owned specialty running gear store located in rural Northeast Texas. Since the owners requested anonymity, the hypothetical names within this paper are Mr. \& Mrs. Jay Jordan with an assumed store name of Fancy Feet Running Gear (FFRG). The store operates in the textile apparel footwear and accessories industry and specializes in the sale of a range of specialty running shoes. It also offers complementary apparel, accessories, and gear to support outdoor activities.

Foot Locker Incorporated is the industry leader with approximately 35 percent of the industry revenue (Yahoo, 2016). Other notable players are Nike and Adidas that benefit from vertical integration of market barriers faced by smaller companies that pay wholesale prices. FFRG is indicative of the smaller players in the industry in that it is independently owned and caters to a niche market within a geographic area.

Founded only two years ago, FFRG emerged from a need and entrepreneurial vision. Mr. Jordan had a business degree, and in addition to working full-time, he was member of a small and dedicated running group and was often called upon for his expertise in specialty running shoes and marathon training techniques. After working in the manufacturing industry during the Recession of 2008, Mr. Jordan realized that his intrinsic value which had been derived from industry management had diminished as the economy deteriorated. Out of frustration, he acknowledged that his passion resided in his feet. Mr. Jordan attributed 
the career change from manufacturing management to small business owner as an avenue to an improved quality of life.

After researching companies and franchise opportunities Mr. Jordan pursued a franchising license with Fleet Feet that was eager to engage in an agreement if he would agree to locate to Tyler, Texas. Unable to persuade the franchisor into a license agreement for a location in a town with a population under 20,000, Jordan founded FFRG.

The company offers shoes and shoe fitting services for running, walking, working, or simply comfort. Inserts both over the counter and fitted to the individual are parts of the product mix. The staff can provide customers with a visual assessment of their unique foot strike and make product recommendations using its in-store treadmill and gait analysis software. To accompany the main products, FFRG sells high-quality socks, sandals, clothing, compression sleeves, sunglasses, pet gear, and hydration and nutrition products.

This small business is located based in East Texas with a distribution agreement of a few brands of running shoes including Brooks, ASICS, and Nuun. The store volume attracted other well-known running and walking shoe brands such as Saucony, Hoka, Pearl, New Balance, Under Armour, Mizuno, Nike, Inoy.

The company's vision is to create an environment that enables healthy balanced lifestyles. The owner described the organization's mission to provide customer service and products to people who want to live well. He also stated that FFRG is dedicated to creating a comfortable shopping experience that is inspirational and promotes the company's vision. The customer base ranges from teenagers to senior citizens (Blevins, 2016).

In addition to the owners, the company employs two workers. Mr. Jordan stated, "Our employees are educated with knowledge about running. They know our products and how to use them" (Blevins, 2016). He also stressed the necessity to recruit, train, develop, and retain associates with goals aligned with the FFRG mission. The store offers specialized services and product expertise that creates a utility not consistently available in larger athletic chain stores. One employee is a military service veteran while the other is enrolled in the physical therapy assistant program at the local community college. The employee training program is based upon the training model implemented by a larger running specialty chain. The owners and employees continue online training offered by vendors. The Jordan's stressed the importance of continuing education alongside staff and making the training available while employees are on the clock. Schedules are set to best support the employees as customer service and employee expertise are the forefront of the business. Job requirements include routine running events (Blevins, 2016). Human resources are vital to this specialty retail company operating in a small geographic location.

FFRG has a reputation of providing superior customer service and subject matter expertise in the running trade arena. In addition to specialty products, the company offers personal coaching, weekly group runs, and a newsletter. The community interaction and training services support the FFRG vision and mission and a realization of customization as defined by Tracey and Wiersema (1995) as "the focus on the delivery of - not what the market wants but what specific customers want...cultivating relationships... and satisfying unique needs, which often only they, by virtue of their close relationship with-- and intimate knowledge of - the customer, recognize...with the best solution for the client by going the extra mile" (p. xiii).

As avid supporters of the military, the Jordans are enthusiastic in their philanthropic mission to combat PTSD. The company hosts bi-weekly running sessions with veterans to enrich the lives of solders with physical and social activity.

\section{SWOT ANALYSIS}

A SWOT analysis is a tool used to examine the situation and environment of a company. The acronym stands for strengths, weaknesses, opportunities and threats. A SWOT analysis was performed on FFRG to provide a framework for analyzing the four elements of the company's internal and external environment. This provided a "raw material" listing of conditions both inside and surrounding the company. By systematically evaluating all four factors, a company can develop the best strategies for gaining a competitive advantage (Kohli, Ajay, \& Jaworsk, 1990). 
The framework for FFRG's SWOT analysis appears below in Figure 1. An examination of the company's functional areas such as marketing, market analysis, information technology, and human resources provided an evaluation of internal and external strengths and weaknesses.

\section{FIGURE 1 \\ ELEMENTS OF SWOT ANALYSIS}

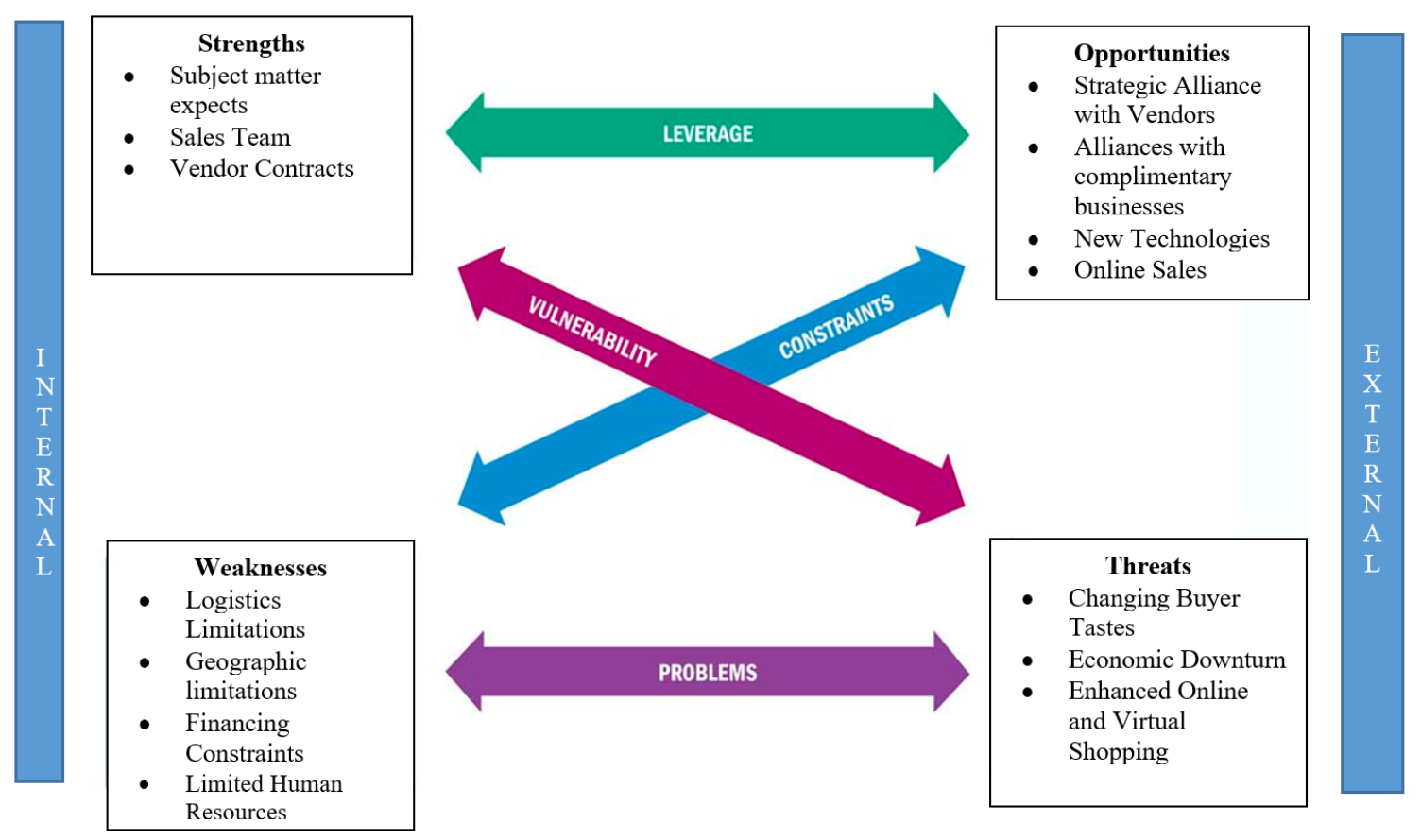

Company internal strengths and weaknesses are recognized by customers (Rumelt, Richard, Schendel, \&Teece, 1991). A key strength for FFRG is the customer's positive image of the company's brand. Consumers will wait in line to receive a gait analysis and pay premium prices for running, walking, and trail shoes. That positive image is additionally supported by employee survey results that expressed verbal satisfaction with the organization's mission and social responsibility efforts. The strengths of the organization are contractual agreements with specialty vendors that limit competitors' access to the region. The sales team customer service supports the organization's strategic vision to create health balanced lifestyles.

Weaknesses include the absence of advanced technologies that are available and maintained at larger specialty running stores. Market saturation is a critical internal concern as the small geographic area and limited logistics prohibit organizational expansion that a larger city can provide. The organization has limited storage space, distribution capabilities, human resources, and inventory management to support online sales. The small town restricts human resource availability. Store sales do not support premium salaries to attach employees to the area. A small workforce constrains the managerial capacity to provide a continuity of customer care for the long-run.

The SWOT analysis also provided a list of external opportunities and threats FFRG is likely to face. Threats are an economic recession that limits customers' willingness and ability to pay a premium for a hobby. The trends of the fitness market may compromise FFRG if running becomes a fad of the past. As online shopping and customer education regarding running shoes and equipment becomes prevalent, the customer can conveniently purchase running and walking shoes online. The stores top brands are received from companies outside the United States. A change in federal regulation or a trade restriction can threaten the organization's supply chain. 
Opportunities include new technologies that improve customization with more efficiency and effectiveness. The Internet, from the technological segment, has wide-reaching impacts to improve sales. Additionally, the area has a Pet Resort that offers doggy daycare. The daycare provides a strategic alliance prospect with FFRG. The organization is a sponsor of the Wounded Warrior Project and hosts bi-weekly running sessions with former military members. FFRG and the local Pet Resort are jointly researching training options to host daily fitness sessions that pair dogs with a local service member from the military running group. Dog owners have been requesting regular exercise for the dog's physical and mental health and are willing to pay a premium price. This strategic alliance would extend service offerings for both the Pet Resort and FFRG.

\section{ORGANIZATION STRATEGY}

\section{Values Model Analysis}

Management consultants, Treacy and Wiersema (1995) approached market leadership and productivity by modifying Michael Porter's (1980) five forces model (Weber \& Polo, 2010). The original Porter five forces included: suppliers, rivalry within an industry, substitute products, customers, and new entrants. Although Porter's model has been widely discussed and utilized, Treacy and Wiersema (1995) provided an alternative that addressed greater specificity and refinement of the forces.

Strategies focused on creating customer value are built on distinct market identity and target market capabilities that are used to direct internal processes. Treacy and Wiersema (1995) state "The message of the Discipline of Market Leaders is that no organization can succeed today by trying to be all things to all people" (p. xiv). Treacy and Wiersema (1995) propose that superior strategies are based on delivering customer value in one of three distinct ways:

1. Operation excellence is the combination of quality, price and ease of purchase unmatched by competitors. Operational excellence companies possess efficient production methods, standardization, centralized operations, and a culture that rewards efficiency (Treacy \& Wiersema, 1995).

2. Product leadership represents the continuous search for the best product (Treacy \& Wiersema, 1995). The authors describe this type of organization as continually pushing its products into the area of the unknown or the highly desirable. This vector is focused on creativity, research, and development. Product leadership companies' offer specialized products typically purchased less frequently than operation excellence organization offerings (Treacy \& Wiersema, 1995).

3. The focus of the customization is the pursuit of innovative products and services. The customer is presented with unique solutions, superior goods and services, and long-term relationships that build customer loyalty. Customization providers explore customer needs and limitations while providing superior goods and services.

Each vector requires a specific operating model regarding processes, business structure, management system and culture. Treacy and Wiersema (1995) proposed the above forms of strategic disciplines are necessary to achieve and maintain market leadership. Value proposition is presented as an implicit promise an organization makes to deliver a combination of values such as price, quality, selection, and convenience. The value proposition models shown below portray a visual of operating processes, management systems, employee expertise, and culture that give an organization the capacity to deliver on its value propositions (Treacy \& Wiersema, 1995).

\section{Values Model Analysis of FFRG Owner}

Appendix A contains survey questions and responses posed to FFRG owners. Figure 2 represents the plot of the owner concept and placement of FFRG in relation to the value model. Both owners view the organization as appealing to a niche market and in the product leadership vector. Customization is viewed as being very strong from the owner's perspective. The Jordans view each customer sale as unique. The owner expectation regarding operational excellence appeared to center around the pricing structure dictated 
by the vendors and convenience. Overheard, inventory controls, efficiency, or other cost efficiency measures did not appear to be critical factors concerning the business owners directly related to customer preferences.

FIGURE 2

VALUE MODEL STRATEGIC COMPANY OWNER GRID

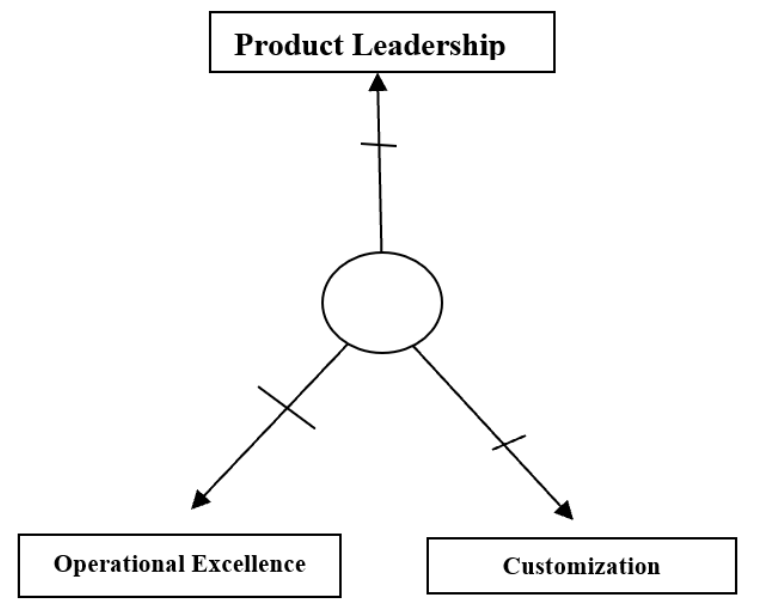

\section{Values Model Analysis FFRG Employees}

FFRG is a small company with only two employees. The following section contains the survey question and responses posed to FFRG employees. Figure 3 represents the plot of the employee concept of the placement of FFRG in relation to the value model. The employees are personally vested in customer relationships. The employees view the company as providing superior products. Additionally, perhaps because of the unique training sessions and different running groups, the employees appear to view the organization as providing a unique product that is customized. The employee grid reflects a slightly higher mark for customization vector as compared to the same vector placement of the owners.

\section{FIGURE 3}

\section{VALUE MODEL STRATEGIC EMPLOYEE GRID}

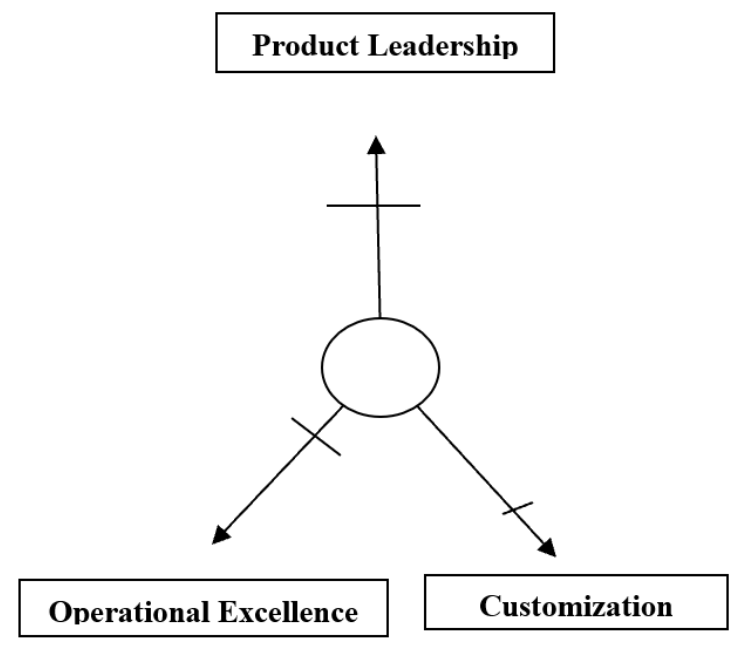




\section{Values Model Analysis FFRG Customers:}

Appendix B contains the survey question and responses posed to FFRG employees. Figure 4 represents the plot of the customer concept of the placement of FFRG in relation to the value model. Customers appreciate the specialized products and unique features of the training and running clinics. However, the convenience of shopping locally was most mentioned most often in this category of surveys over the owners and employees.

\section{FIGURE 4 \\ VALUE MODEL STRATEGY CUSTOMER GRID}

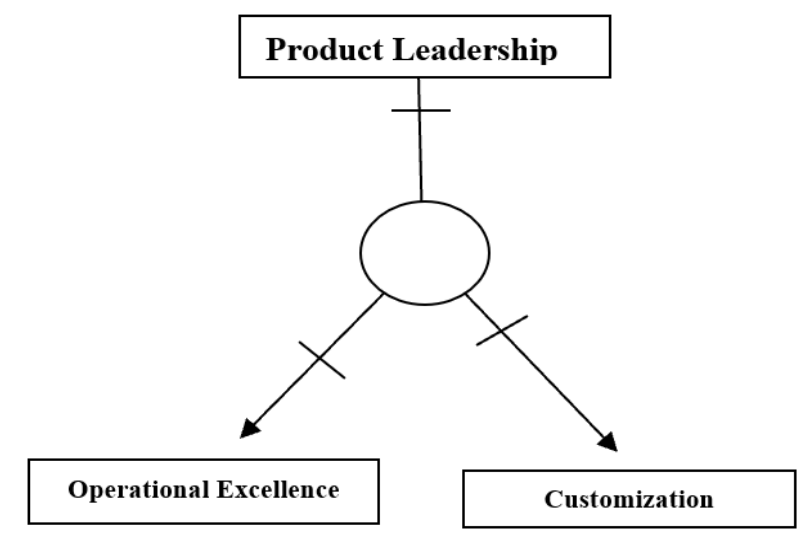

The segmentation of FFRG's market provided a distinctive characterization based on various demographic and socioeconomic characteristics. According to the organization's owners, the majority of customers were Generation Xers. The fastest growing segment is the Millennials. The majority of shoppers are educated and comparison shop. The customer base consisted of an equal balance of male and female customers (Blevins, 2016). Male shoppers tended to identify a product and make the purchase. Female shoppers did more browsing and were more likely to visit the store multiple times before making a purchase. According to Naver, Slater, and Tiete (1998) the psychographic segmentation of a market can be categorized into similar social habits. The feedback gathered from owners, employees, and customers reflect a customer base that has similar social habits and health-driven attitudes and lifestyles.

\section{CONCLUSION}

Figure 5 provides a comprehensive view of owner, employee, and customer perspectives. Overall, the product leader vector is most appropriate for this company. Employees expressed the ability to be creative, conduct research and have a level of autonomy. The store products and brands are higher quality reflected in the higher priced shoes and accessories that align with customer expectations in the product leader vector. Although the operational excellence is not the highest ranked among the three vectors, shoppers are attached to the convenience of local shopping. FFRG appears to recognize emerging needs of the target market and assess customer response to the organization's strategic decisions. 


\section{FIGURE 5 \\ FFRG PRODUCT LEADER ORGANIZATION VECTOR}

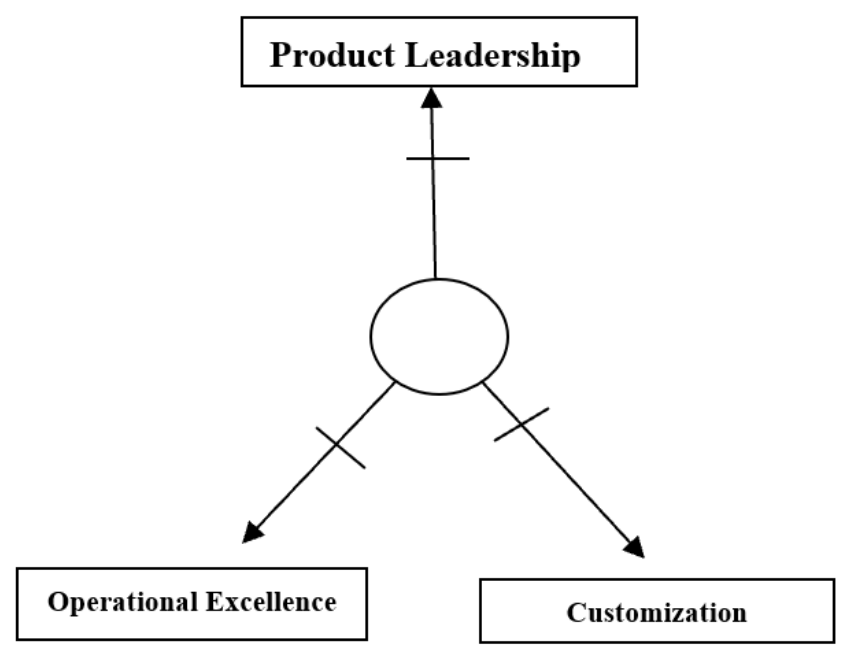

\section{REFERENCES}

Blevins, M. (2016, October 6). Owner. (J. Cooper, Interviewer).

Kohli, A.K., \& Jaworski, B. (1990, April). Market orientation: The construct, research propositions, and managerial implications. Journal of Marketing, 54, 1-18.

Narver, J.C., Slater, S.F., \& Tietje, B. (1998). Creating a market orientation. Journal of Market-Focused Management, 2(3), 241-255.

Rumelt, R.P., Schendel, D., \& Teece, D. (1991, Winter). Strategic management and economics. Strategic Management Journal, 12, 5-30.

Treacy, M., \& Wiersema, F. (1995). The discipline of market leaders: Choose your customers, narrow your focus, dominate your market. Basic Books.

Weber, W., \& Polo, E.F. (2010). Evolution of generic competitive strategies and the importance of Michael E. Porter. Revista de Gestão USP, 17(1), 99-117.

\section{APPENDIX A: INTERVIEW QUESTIONS FOR FFRG OWNERS}

Question 1: Tell me about your organization.

Answer: We are a family owned specialty business specializing in running and walking shoes and equipment.

Question 2: What are the strengths of your organization?

Answer: Our strengths are that we are small, flexible, niche-type organization that offers specialty products that are not available physically within a 60 mile radius. Our prices are also strengths as they are established by vendors and are consistent from store to store and we do not have to worry about a competitor beating our prices.

Question 3: Describe positive factors that influence your organization?

Answer: The millennials have really helped. Millennial shoppers are anti-chain and shop for a cause. Our most positive social media comments supporting shopping local are derived from the millennial group. Our geographic location is centered amongst active running clubs to the north, south, east, and west. The running market has exploded in the past 10 years and we are capturing an enthusiastic crowd that likes to socialize and run. Our store location with close proximity to a beautiful park full of shade trees really helps 
us support running clinics almost daily. The warm climate allows for running the full calendar year without much break of routine running sessions.

Question 4: Describe negative factors that influence your organization.

Answer: More seasons would provide more shopping and clothing and apparel options. Online sales are a big negative to us. A customer can come in and get a gait analysis and a shoe fit recommendation and go online and purchase the shoe. For now, the vendor prices are consistent, however, there is no guarantee that online shopping will not eventually hurt brick and mortar stores. We do not have a solid online sales program to compete if the pricing structure changes. The specialty shoes we carry do not vary much from year to year. So if you know that you need extra arch support, you can go online next year and order the same shoe. Our running clinics are designed for optimal form and technique so customers can broaden their shoe options yet many stay with the same style of shoe. Our strength can also work against us. It took about 6 months to completely train the employees and they went through training at different times so our time as owners was not at its highest efficiency either. We cannot afford high turnover and the employees will be hard to replace and hard to attract. We get lots of applications, however, there are not a lot of good fits with our mission. This is not a typical part-time job. Quality employees are hard to find and will be hard to replace without a more efficient training and development program.

Question 5: Why do customers buy from you?

Answer: We provide a high level of expertise individually catered to the client. Our service level is the best. Hibbits sends running customers here because they do not want to assist runners. Dick's Sporting Goods tried to streamline the gait analysis in all of their stores and it was only successful in one store and that was specifically tied to one shoe manager and when that manager left Dick's discontinued that service. There are four individuals here that know that software and know the shoe products very well. The customers like the individual attention and time we spend focusing solely on them. We host $5 \mathrm{~K}$ and $10 \mathrm{~K}$ runs every Saturday morning. Additionally, one of us is at the park almost every day either with an individual that we are training or with a running group. Customers shop here for store identity and because it's local and many support local. Our social media presence is by far our greatest marketing to bring in new customers.

\section{APPENDIX B: INTERVIEW QUESTIONS FOR FFRG EMPLOYEES}

Question 1: Why do customers shop here?

Answer 1: Honestly, most of our customers come here after they have been injured. They do not want to be in pain anymore and realize they need good shoes. We get a lot of referrals from the orthopedic clinic. We always extend invitations on social media to all orthopedic and PT clinics in the area. Several are in our running groups and we get a lot of referrals from the medical community. Customers come here to get a prescription for a shoe.

Answer 2: I run with a lot of our customers. They shop here because they have gotten to know us. I was in the Marines for almost 20 years before I got out and moved back home. I run with a lot of police officers and veterans. I talked the owner into giving discounts to policy and military. The owners are super nice to employees and customers. I think customers shop here because of the way they are treated and there isn't anywhere else to go to get the coaching we provide to our customers. I do a lot of personal training. All four of us do. That is what I like best. Each person is a challenge. Some want to run faster race times. Some have never ran before and just want to run a mile without stopping. Some are training for ultra runs and triathlon runs. James has to train the triathlon runners. If they are not customers before they sign up for training or running clinics then they quickly become customers. Our customers want it all. The shoes, socks, everything. The vendors are great to our customers. Customers know there is going to be a vendor hosting a run almost every Saturday. We also have unique items for dogs. Many of our customers run with their dogs. Some customers don't run. They come in because we have great safe dog gear and they end up buying

142 American Journal of Management Vol. 21(6) 2021 
walking shoes. Now some of them join our weekly Run With the Big Dogs walk in the park. It is every Tuesday. Dog lovers really love a company that caters to dogs. We have safety harnesses and reflective vests for runners and their dogs. We are trying to partner up veterans and the dogs from the local dog daycare place so the dogs get exercise and the veterans get out and get exercise and that is supposed to

help with PTSD and other things veterans fight off. Some customers come in because they hear about us on Facebook.

\section{APPENDIX C: INTERVIEW QUESTIONS FOR FFRG CUSTOMERS}

Question: Why do you shop here?

Answer 1: I like Brooks shoes. They are the only ones in town that carry Brooks. Plus I like to shop local.

Answer 2: I had a gift certificate.

Answer 3: They have the friendliest staff. I had a foot analysis and I cannot believe how much I love my shoes. My feet don't hurt at the end of the day like they used to and I love to shop in my hometown.

Answer 4: When my dog died they sent me a card because one of my friends is in their dog walking group. I couldn't believe it. They invited me to join their walking group in the park. I went in the store and bought a pair of walking shoes and walk in the park either with them or alone almost every day.

Answer 5: I am a big fan of Luke's Locker, but FFRG is in town. They carry many of the same brands. I prefer to shop locally.

Answer 6: I've tried to shop there two times now. They never have my size. I would love to shop local, but they don't have my size.

Answer 7: The gait machine that measures your foot strike and stride and the staff are great. They tell you what type of shoes you need.

Answer 8: Convenience and selection is much better than at Hibbits. I had no idea they had running clubs and coaches until I came in. Now I'm here almost every day because there is a different type of clinic for walking or running in the mornings or on my lunch hour.

Answer 9: I started running with Jay on the FFRG Saturday runs. He is the best and has the best service and the shoes are high quality.

Answer 10: FFRG has a great selection of high quality running shoes. The best part is the convenience of hometown shopping. 